\title{
Optimization of Lyophilized LAMP and RT-PCR Reaction Mixes for Detection of Tuberculosis
}

\author{
Esra AGEL $^{1^{*}}$, Hasan SAGCAN ${ }^{2}$
}

\begin{abstract}
Undoubtedly, one of the most infectious diseases in the world is tuberculosis. Key factor for tuberculosis control is to prevent possible contagion with rapid diagnosis and effective treatment. The culture method, which it takes several weeks to obtain results, is the gold standard method for laboratory diagnosis of tuberculosis. In order to prevent possible contagion of tuberculosis, diagnosis must be made in short time and treatment should be started as soon as possible. Normally, clinical samples are studied in advanced laboratories designed for this purpose. However, especially after the screening in rural areas, the transmission of the samples to the centers has many negative effects on the clinical material. Therefore, the latest trend molecular techniques in microbiological diagnosis are developing into point of care systems that can be applied in the field without laboratory infrastructure. The major challenge for molecular-based point-of-care tests is the need to store polymerase enzymes and some of the ingredients used in the cold chain. The aim of this study is to increase the resistance of the amplification reaction mixtures by lyophilizing the tuberculosis diagnosis. Lyophilization was performed on Loop-mediated isothermal amplification (LAMP) and Real-time PCR mixtures. For the lyophilization of LAMP and RT-PCR mixtures, two different experimental setups were tried from the literature except for the developed content. Chemicals such as stachyose, trehalose, glycerol and PEG 8000 are widely using as cryoprotectants. As a result, the developed content (0.5\% PEG 8000, $2.0 \%$ Stachyose) was determined the best cryoprotectant mixture. Accordingly, amplification mixtures can be produced with the developed lyophilization method and point of care kits can be developed.
\end{abstract}

Keywords: Lyophilized master mix, Loop-mediated isothermal amplification, LAMP, Real-time PCR, M. tuberculosis

${ }^{1}$ TUBITAK Marmara Research Center, Materials Institute, Kocaeli, Turkey. ${ }_{2}^{2}$ Istanbul Medipol University, Vocational School of Health Services, Department of Medical Laboratory Techniques, Istanbul, Turkey.

Corresponding Author: Esra AGEL *E-Mail: esra.agel@tubitak.gov.tr

DOI: $10.2478 /$ ebtj-2020-0027

(๑) 2020 Authors. This work was licensed under the Creative Commons Attribution-

\section{Introduction}

Tuberculosis is a re-emerging infectious disease that causes death by outbreak (1). Mycobacterium tuberculosis which is the causative agent of tuberculosis infection is spread through droplet nuclei up to 5 microns in diameter (2). Depending on the environmental conditions, these small particles may remain suspended in the air for several hours. Besides, the infectious dose ( $<10$ bacilli) is very low and therefore has the potential to be used in bioterrorism attacks (3). According to the World Health Organization (WHO), tuberculosis is one of the most important causes of death worldwide. Only in 2018, ten million fell ill with tuberculosis and 1.5 million died (4). Rapid diagnosis of tuberculosis has critical importance. However, gold standard method which is culture method takes a few weeks (5). But to prevent the spread of the disease, there is a critical need for quick, sensitive, reliable, point-of-care and economical methods for the laboratory diagnosis of tuberculosis (6).

DNA based amplification reactions and antigen-antibody based methods are available for the diagnosis of tuberculosis except for the culture method which is the gold standard (7). However, since the diagnosis of the disease takes a long time with the culture method, treatment is delayed. Also, because of the low sensitivity of the antigen-antibody 
based methods, it is a needed to the rapid and sensitive method for diagnosis of tuberculosis. Although nucleic acid based diagnostic systems are advantageous in terms of time and sensitivity, many of them have complicated protocols and depend on complex devices (8).

Molecular methods, especially PCR, have reached an important point for the diagnosis of tuberculosis (9). In addition to the commercially tuberculosis PCR detection kits, many laboratories have their own in-house methods (10).

However, PCR methods used in routine require specialists due to their complex processes and cold-chain transportation needs. Generally, PCR studies are performed with small volumes such as 1-10 $\mu \mathrm{l}$ and the smallest error can have critical results (11). Therefore, the method to be developed should be as low as possible to minimize the person's error.

In recent years, scientists have been working on the use of DNA amplification reactions in the point of care tests (12). The loop-mediated isothermal amplification (LAMP) method developed by Notomi et al. (2000) is more sensitive than other PCR methods, because of using 4 or 6 different primers that recognize 6 or 8 different regions on the target gene $(13,14)$. Due to its primers design and Bst DNA polymerase, the method does not require temperature cycling (15). Whereby its ability to perform at a constant temperature, it has become frequently used in point of care tests and microfluidic chips $(16,17)$. Particularly, the fact that the detection of the products formed at the end of the reaction can be made with the naked eye or the lateral flow test strips makes it widely used in field studies (18).

Despite the advantages of using DNA amplification methods for diagnostic purposes, there are still challenges that need to be overcome (19). Standardization of reaction mixture preparation is important for the accuracy and sensitivity of the results. It is difficult to ensure standardization, especially in field conditions, as the ingredients must be stored at $-20{ }^{\circ} \mathrm{C}$ and work in the cold chain. Lyophilization is a protection method used in amplification reactions to make the mixtures resistant to environmental conditions (20). The lyophilization process, which is also used in commercial kits, extends the lifetime of PCR mixtures up to 1 year (21).

The aim of this study was to extend lifetime and resistant to environmental conditions of LAMP and RT-PCR mixtures via lyophilization. Accordingly, three different lyophilization methods were tried and results were compared.

Table 1. Cryoprotectant mixtures and amount of ingredients

\section{Materials and methods}

\section{Bacterial strains and DNA isolation}

Mycobacterium tuberculosis $\mathrm{H} 37 \mathrm{Rv}$ reference strains were provided by Atatürk Chest Diseases and Chest Surgery Training and Research Hospitals. Reference strains grown on Lowenstein-Jensen medium was homogenized in physiological saline solution $(0.9 \% \mathrm{NaCl})$. DNA of the reference strains was extracted by QIAGEN QIAamp DNA mini kit, according to the manufacturer's instructions. The purity and quality of DNA were controlled using Implen NanoPhotometer (Implen $\mathrm{GmbH}$, Germany).

\section{LAMP and RT-PCR Assay}

M. tuberculosis specific LAMP primers were designed using PrimerExplorer V5 according to IS6110 gene (GenBank accession no: X17348). LAMP reaction was performed in $25 \mu \mathrm{l}$, containing $0.2 \mu \mathrm{M}$ each outer primers (F3 and B3), $0.8 \mu \mathrm{M}$ each inner primers (FIP and BIP), $20 \mathrm{mM}$ Tris- $\mathrm{HCl}(\mathrm{pH}: 8.8), 10$ $\mathrm{mM} \mathrm{KCl}, 10 \mathrm{mM}$ (NH4)2SO4, 5 mM MgSO4, 0.4 mM dNTP, 2 $\mathrm{U}$ Bst polymerase and $5 \mu \mathrm{l} \mathrm{DNA}$ sample. For isothermal amplification, samples were incubated at $71.4^{\circ} \mathrm{C}$ for 60 minutes. After amplification, Bst polymerase inhibition was performed at $80{ }^{\circ} \mathrm{C}$ for $10 \mathrm{~min}$. LAMP products were run $2 \% \mathrm{w} / \mathrm{v}$ agarose gel electrophoresis in 90V for $60 \mathrm{~min}$. IS6 (5'-GGCTGTGGGTAGCAGACC-3'), IS7(5'-CG GGTCCAGATGGCTTGC-3') primers and IS6110 Taqman probe (5'-(FAM)- TGTCGACCTGGGCAGGGTTCG-(TAMRA)-3') were used in RT-PCR method described by Desjardin et al. (1998) (22). Real Time PCR was carried out in $25 \mu \mathrm{l}$, containing $0.2 \mathrm{mM}$ dNTP, $0.2 \mu \mathrm{M}$ IS6 and IS7, $0.1 \mu \mathrm{M}$ probe, $1 \mathrm{U}$ Taq polymerase, $5 \mathrm{mM} \mathrm{MgCl} 2$, and 5 $\mu \mathrm{l}$ DNA sample. PCR reaction was performed with BioRad CFX96 with following conditions: $50^{\circ} \mathrm{C}$ for $2 \mathrm{~min}, 95^{\circ} \mathrm{C} 5 \mathrm{~min}$, and 45 cycles of $94^{\circ} \mathrm{C} 30 \mathrm{~s}$ and $68^{\circ} \mathrm{C} 1 \mathrm{~min}$.

The specificity, sensitivity, positive predictive value and negative predictive value were determined from the results based on a calculation previously reported (23).

\section{Lyophilization of amplification mixtures}

Two different cryoprotectant mixtures which described by Sharma et al. (2014) and Klatser et al. (1998) (20,24), except our mixture was used for LAMP and RT-PCR methods. The tested lyophilization contents in this study are given in table 1. Lyophilization was performed on the Christ Epsilon 2-6D LSCplus freeze dryer and the protocol is given in table 2. Am-

\begin{tabular}{|c|c|c|}
\hline Mixtures & Cryoprotectants & Amount \\
\hline \multirow{3}{*}{ 1. mixture (Sharma et al. 2014) } & PEG 8000 & $0.1 \%$ \\
\hline & Glycerol & $2.0 \%$ \\
\hline & Trehalose & $0.1 \mathrm{mM}$ \\
\hline 2. mixture (Klatser et al. 1998) & Trehalose & $5 \%$ \\
\hline \multirow{4}{*}{ 3. mixture (This study) } & PEG 8000 & $0-0.1-0.2-0.5 \%$ \\
\hline & Stachyose & $0-1.0-2.0 \%$ \\
\hline & Glycerol & $0-1.0-2.0 \%$ \\
\hline & Trehalose & $0-1.0-2.0-5.0 \%$ \\
\hline
\end{tabular}


Table 2. The protocol of freeze dryer

\begin{tabular}{|c|c|c|c|c|}
\hline Stage & Steps & Pressure & Temperature State & Time \\
\hline Pre-chill & & 760 Torr & Shelf at $-55^{\circ} \mathrm{C}$ & $60 \mathrm{~min}$. \\
\hline Load tray & & 760 Torr & Hold at $-55^{\circ} \mathrm{C}$ & - \\
\hline Vacuum & & 760 Torr- 100 mTorr & Hold at $-55^{\circ} \mathrm{C}$ & $420 \mathrm{~min}$. \\
\hline & 1 & 100 mTorr & Hold at $-55^{\circ} \mathrm{C}$ & $120 \mathrm{~min}$. \\
\hline & 2 & 100 mTorr & Ramp from $-55^{\circ} \mathrm{C}$ to $-37^{\circ} \mathrm{C}$ & $480 \mathrm{~min}$ \\
\hline \multirow{2}{*}{ Primary Drying } & 3 & 100 mTorr & Hold at $-37^{\circ} \mathrm{C}$ & $360 \mathrm{~min}$ \\
\hline & 5 & 100 mTorr & Ramp from $-37{ }^{\circ} \mathrm{C}$ to $+10^{\circ} \mathrm{C}$ & $240 \mathrm{~min}$ \\
\hline & 6 & 100 mTorr & Hold at $+10^{\circ} \mathrm{C}$ & $120 \mathrm{~min}$ \\
\hline
\end{tabular}

plification reactions were performed on a lyophilized mixture with $20 \mu \mathrm{l}$ of molecular grade water and $5 \mu \mathrm{l}$ of DNA sample (Tab. 1 and Tab. 2).

\section{Thermal stability and analytical sensitivity of lyophilized mix-} tures

The lyophilized LAMP and RT-PCR mixtures were stored at $-20^{\circ} \mathrm{C}, 4{ }^{\circ} \mathrm{C}$ and room temperature to reveal the thermal stability of lyophilized mixtures. Three sets of vials were used from each of the stored temperatures. Reaction mixtures were used for amplification on $1^{\text {st }}, 2^{\text {nd }}, 4^{\text {th }}$ weeks and $2^{\text {nd }}, 6^{\text {th }}$ and $12^{\text {th }}$ months.

Serial dilutions between $10^{5} \mathrm{CFU} / \mathrm{ml}$ and $10^{1} \mathrm{CFU} / \mathrm{ml}$ of $\mathrm{M}$. tuberculosis samples were used to determine the limit of detection of the lyophilized LAMP and RT-PCR mixtures. M. tuberculosis free sputum DNA was used as the negative control. The prepared dilutions were studied using both lyophilized mixtures and freshly prepared mixtures.

\section{Results}

\section{Optimal cryoprotectant mixtures}

For the lyophilization of LAMP and RT-PCR mixtures, three different cryoprotectant mixtures were tested. In the studies carried out as a result of the lyophilization process, described by Sharma et al., (2014) and Klatser et al., (1998) $(20,24)$ contents were found to cause inhibition in both amplification reactions which can be shown in figure 2. The cryoprotectant mixture tested for the first time in this study is suitable for LAMP and RT-PCR studies. Accordingly, the cryoprotectant given in table 1 was tested at the indicated concentrations. As shown in figure 2, the cryoprotectant mixture proposed by Sharma et al., (2014) and Klatser et al., (1998) (20,24) has not been successful in our studies (Fig. 1 and Fig. 2).

\section{Thermal stability of lyophilized mixtures}

Lyophilized mixtures were stored at $-20^{\circ} \mathrm{C}, 4^{\circ} \mathrm{C}$ and room temperature to protect from light. Lyophilized samples were tested in 3 replicates, both positive and negative, at 1, 2, 4 weeks, 2, 6 and 12 months. No inhibition was observed at $-20{ }^{\circ} \mathrm{C}$ and $4{ }^{\circ} \mathrm{C}$ conditions for 12 th month. However, the lyophilized samples

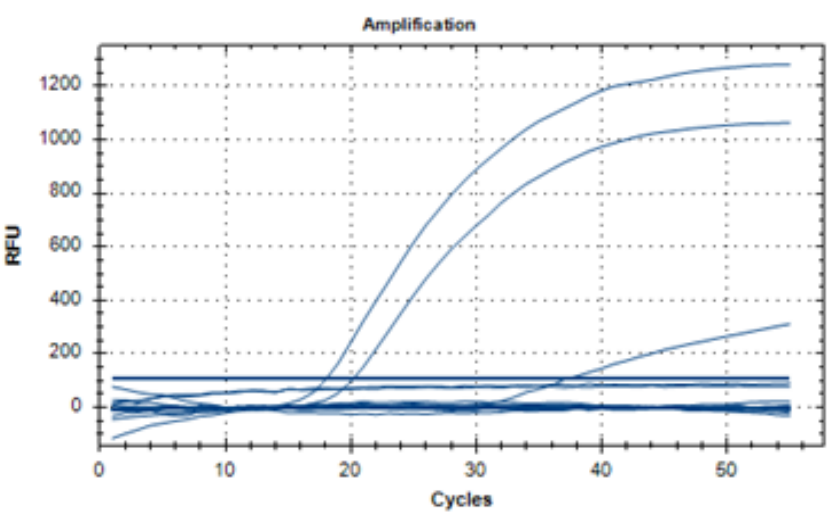

Figure 1. Results of different cryoprelyophilized mixture. 1) Freshly prepared mixture, 2) $(0.5 \%$ PEG $8000+2.0 \%$ stachyose) Cryoprotectant mixture, 3) (0.5 \% PEG $8000+1.0 \%$ stachyose) Cryoprotectant mixture.

stored at room temperature did not work after 2 weeks (Fig. 3).

\section{Analytical sensitivity of lyophilized mixtures}

Serial dilutions between $10^{5} \mathrm{CFU} / \mathrm{ml}$ and $10^{1} \mathrm{CFU} / \mathrm{ml}$ of the M. tuberculosis were used to measure the detection limit of lyophilized LAMP and RT-PCR assay. The limit of detection studies was performed in three replicates and parallel with lyophilized mixtures and the newly prepared mixtures. As a result, the detection limit of lyophilized and newly prepared mixtures was $10^{2} \mathrm{CFU} / \mathrm{ml}$ in LAMP assay. The detection limit of lyophilized and newly prepared mixtures was $10^{1} \mathrm{CFU} / \mathrm{ml}$ in RT-PCR assay (Fig. 4 and Fig. 5).

\section{Discussion}

The culture method is still the gold standard for the diagnosis of tuberculosis (25). However, in recent years, molecular tests have been studied for rapid diagnosis in the field. Lyophilization of the master mixes is an indispensable requirement for the developed molecular tests to be used in the field. There are 

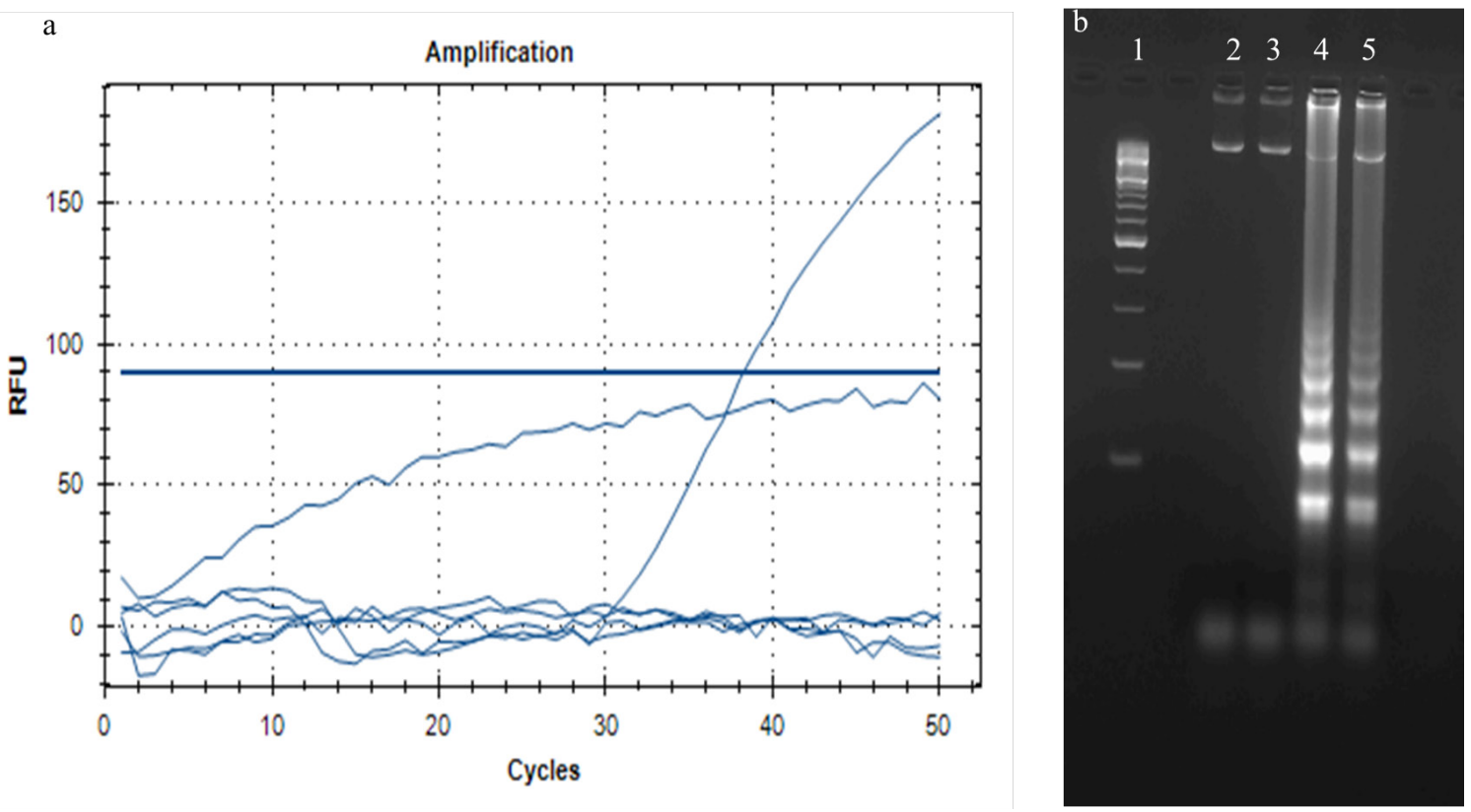

Figure 2. Results of lyophilized RT-PCR (a) and lyophilized LAMP (b) mixture. a: only 3. cryoprotectant mixture has positive result in RT-PCR assay. b: Results of LAMP assay 1) DNA ladder (100 bp, NEB), 2) 1. Cryoprotectant mixture, 3) 2. Cryoprotectant mixture, 4) 3. Cryoprotectant mixture 5) Freshly prepared mixture.

different stabilizers used for this purpose such as trehalose, PEG, Stachyose, glycerol $(12,26)$. However, the stabilizers to be preferred must be compatible with the molecular method used. For the lyophilization of LAMP and RT-PCR mixtures, three different cryoprotectant mixtures were tested. In the study of Sharma et al., (2014) (24), the multiplex RT-PCR method was developed for the diagnosis of foot and mouth disease virus (FMDV) and the optimization and validation of the lyophilization of the reaction content was performed. But, the cryoprotectant mixture proposed by Sharma et al., (2014) (24), has not been successful in our studies.

Undoubtedly, diagnostic mixes developed as lyophilized
Week 1
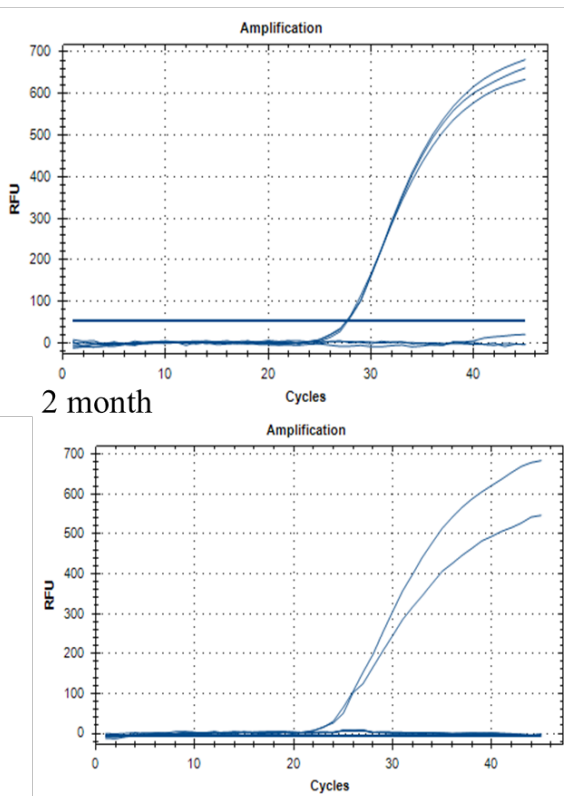

Week 2
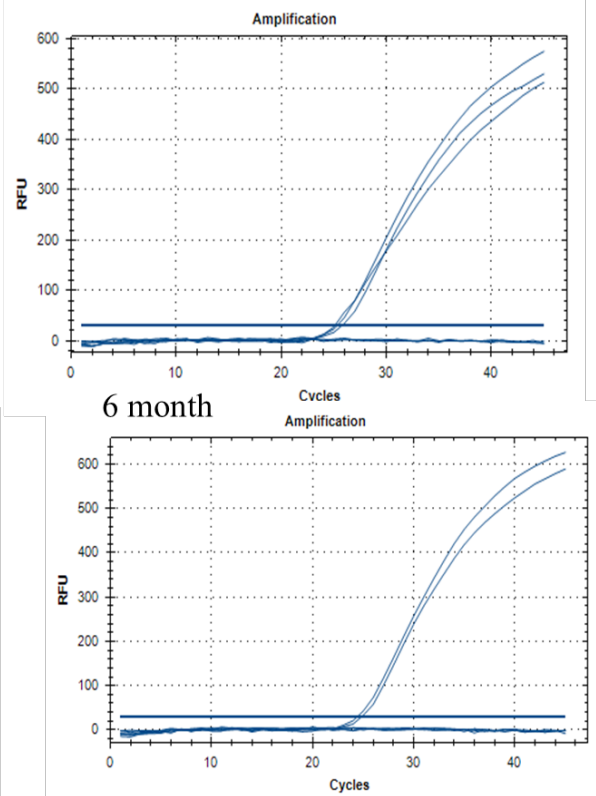

Week 4
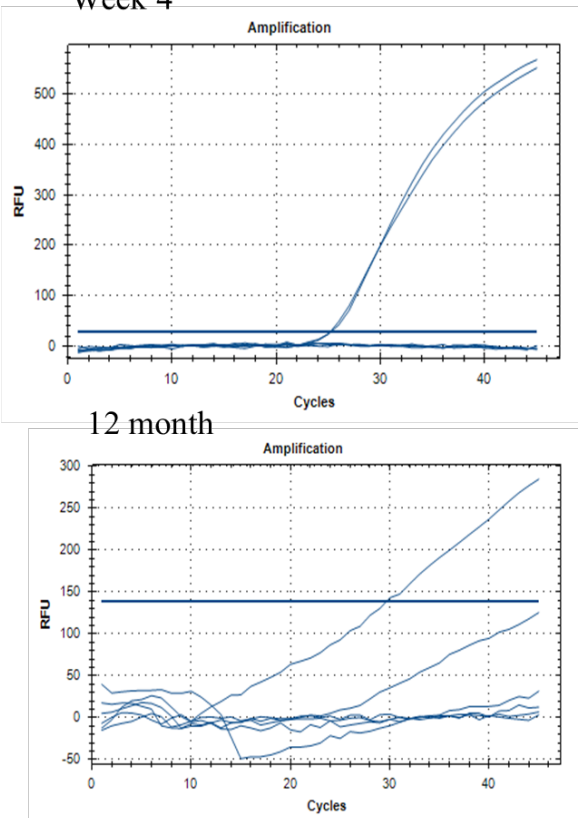

Figure 3. RT-PCR results of thermal stability of lyophilized mixtures 

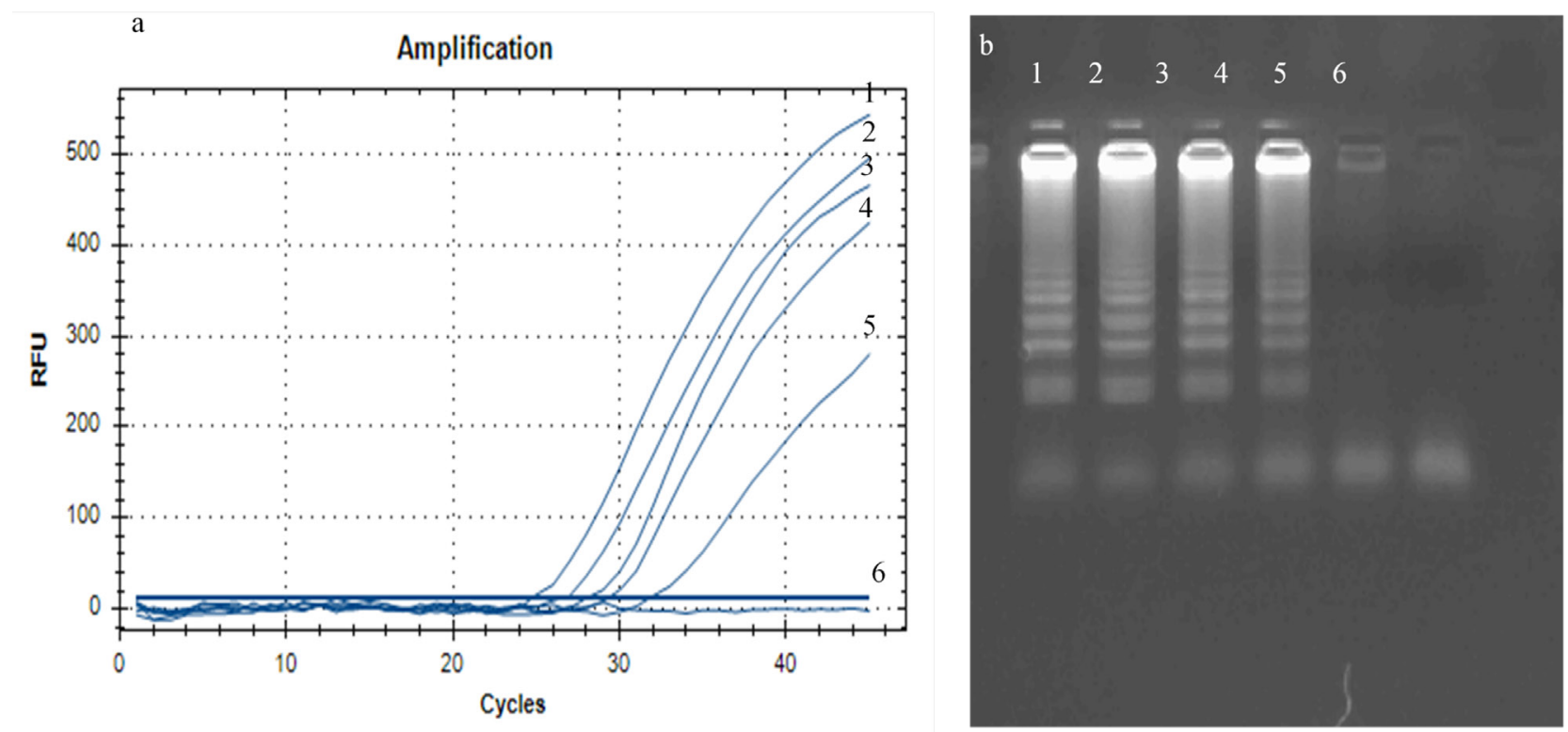

Figure 4. Detection limit results of lyophilized RT-PCR (a) and LAMP (b). a: 1) $10^{5} \mathrm{CFU} / \mathrm{ml}, 2$ ) $10^{4} \mathrm{CFU} / \mathrm{ml}, 3$ ) $10^{3} \mathrm{CFU} / \mathrm{ml}$, 4) $10^{2} \mathrm{CFU} / \mathrm{ml}$, 5) $\left.10^{1} \mathrm{CFU} / \mathrm{ml}, 6\right)$ negative control. b: a: 1) $10^{5} \mathrm{CFU} / \mathrm{ml}$, 2) $\left.\left.10^{4} \mathrm{CFU} / \mathrm{ml}, 3\right) 10^{3} \mathrm{CFU} / \mathrm{ml}, 4\right) 10^{2} \mathrm{CFU} / \mathrm{ml}$, 5) $10^{1}$ $\mathrm{CFU} / \mathrm{ml}, 6)$ negative control

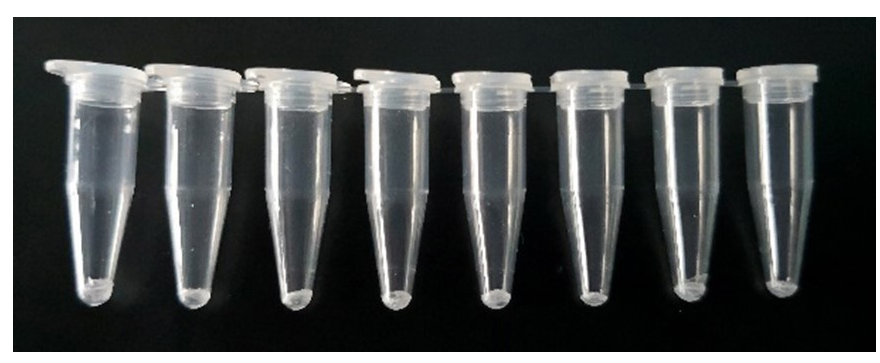

Figure 5. An image of lyophilized mixture in PCR tubes.

have a longer life than non-lyophilized mixes (27). Nevertheless, even if they are lyophilized, these mixtures have certain periods in which they can maintain stability. The stability of the lyophilization developed by this study was evaluated up to 12 mounth at 3 different temperatures $\left(-20^{\circ} \mathrm{C}, 4{ }^{\circ} \mathrm{C}\right.$ and room temperature). All lyophilized samples were assayed with 3 replicates and positive and negative samples. Studies were performed at the $1^{\text {st }}, 2^{\text {nd }}, 4^{\text {th }}$ weeks and $2^{\text {nd }}, 6^{\text {th }}$ and $12^{\text {th }}$ month after lyophilization. Any inhibition was not observed at $-20^{\circ} \mathrm{C}$ and $4{ }^{\circ} \mathrm{C}$ conditions for 12 month but the lyophilized samples stored at room temperature did not work after $2^{\text {nd }}$ weeks. Chua et al. (2011) reported that the lyophilized PCR mixture remains stable for 7.4 months at $24{ }^{\circ} \mathrm{C}$. But unlike our study, the thermal stability of the lyophilized PCR assay was estimated using accelerated aging techniques with elevated temperatures also known as the Q10 method in Chua et al., (2011) study. Furthermore, the thermal stabilization of the lyophilized amplification mixture determined at room temperature for 2 weeks is enough for field studies. In a different study, the stability of the lyophilized mixture was studied at 3 different temperatures (4
${ }^{\circ} \mathrm{C}, 25^{\circ} \mathrm{C}$ and $37^{\circ} \mathrm{C}$ ), over 30 days (28). According to Khazani et al., (2017), the lyophilized PCR mixture was stable for 30 days. Here, it can be said that the type and amount of cryoprotectants used may be important to the stabilization of mixtures.

The infectious dose of many infectious microorganisms is quite low (29). It is very important to determine the infective dose of these pathogens with the methods to be developed for the patient's health. For this purpose, the LOD is determined during the kit development stages. In this study, determination of the limit of detection of the lyophilized master mix was performed. As a result, the detection limit of the lyophilized LAMP master mix was $10^{2} \mathrm{CFU} / \mathrm{ml}$ and the RT-PCR master mix was $10^{1} \mathrm{CFU} / \mathrm{ml}$. Here, it is seen that the lyophilization process does not affect the detection limit of both two methods. In the lyophilization study of the PCR mixture used in the detection of $S$. aureus by Nagaraj et al. (2018) (26), the limit of detection was determined as $10^{6} \mathrm{CFU} / \mathrm{mL}$. Although the limits of detection are different in the studies, especially, parallel results between lyophilized and fresh mixtures demonstrate an important advantage of lyophilization processes.

In conclusion, this study provides a suitable lyophilization process for LAMP and RT-PCR mixtures used in the detection of M. tuberculosis. $0.5 \%$ PEG 8000 and $2.0 \%$ stachyose were found to be suitable as cryoprotectant mixtures. After the stabilization study, it was found that the stabilization of the lyophilized mixture was 2 weeks at room temperature and 12th mounth for the other two temperatures $\left(-20^{\circ} \mathrm{C}\right.$ and $\left.4{ }^{\circ} \mathrm{C}\right)$. Finally, the lyophilization process used in this study did not reveal any negative effects on the detection limits of LAMP and RT-PCR methods. In this study, the cold chain requirement of amplification mixtures, which is an important obstacle for the detection of tuberculosis in the field, was terminated. 
Acknowledgment and/or disclaimers, if any This research was supported by TUBITAK (The Scientific and Technological Research Council of Turkey) under the Project 1003 115R002 entitled "Development of Integrated Microfluidic Chip Based Diagnostic Kit for Sensitive and Rapid Diagnosis of Tuberculosis Infection". Any opinions, findings, and conclusions expressed in this material are those of the authors and do not necessarily reflect the views of TUBITAK.

\section{References}

1. Fauci AS, Touchette NA, Folkers GK. Emerging Infectious Diseases: a 10-Year Perspective from the National Institute of Allergy and Infectious Diseases. Emerging Infectious Diseases. 2005;11(4):519-525. doi:10.3201/eid1104.041167

2. Fennelly KP, Jones-López EC. Quantity and Quality of Inhaled Dose Predicts Immunopathology in Tuberculosis. Frontiers in Immunology. 2015;6(JUN):1-13. doi:10.3389/ fimmu.2015.00313

3. Sakamoto K. The Pathology of Mycobacterium tuberculosis Infection. Veterinary Pathology. 2012;49(3):423-439. doi:10.1177/0300985811429313

4. WHO. WHO | Global Tuberculosis Report 2018.; 2018.

5. Palomino JC. Nonconventional and new methods in the diagnosis of tuberculosis: feasibility and applicability in the field. European Respiratory Journal. 2005;26(2):339350. doi:10.1183/09031936.05.00050305

6. Parsons LM, Somoskovi A, Gutierrez C, et al. Laboratory Diagnosis of Tuberculosis in Resource-Poor Countries: Challenges and Opportunities. Clinical Microbiology Reviews. 2011;24(2):314-350. doi:10.1128/CMR.00059-10

7. He X-Y, Li J, Hao J, et al. Assessment of Five Antigens from Mycobacterium tuberculosis for Serodiagnosis of Tuberculosis. Clinical and Vaccine Immunology. 2011;18(4):565570. doi:10.1128/CVI.00507-10

8. Walker FM, Hsieh K. Advances in Directly Amplifying Nucleic Acids from Complex Samples. Biosensors. 2019;9(4):117. doi:10.3390/bios9040117

9. Balasingham S V., Davidsen T, Szpinda I, Frye SA, Tønjum T. Molecular Diagnostics in Tuberculosis. Molecular Diagnosis \& Therapy. 2009;13(3):137-151. doi:10.1007/ BF03256322

10. Wei Z, Zhang X, Wei C, et al. Diagnostic accuracy of inhouse real-time PCR assay for Mycobacterium tuberculosis: a systematic review and meta-analysis. BMC Infectious Diseases. 2019;19(1):701. doi:10.1186/s12879-019-4273-Z

11. Chua AL, Elina HT, Lim BH, Yean CY, Ravichandran M, Lalitha P. Development of a dry reagent-based triplex PCR for the detection of toxigenic and non-toxigenic Vibrio cholerae. Journal of Medical Microbiology. 2011;60(4):481-485. doi:10.1099/jmm.0.027433-0

12. García-Bernalt Diego J, Fernández-Soto P, Crego-Vicente $\mathrm{B}$, et al. Progress in loop-mediated isothermal amplification assay for detection of Schistosoma mansoni DNA: towards a ready-to-use test. Scientific Reports. 2019;9(1):14744. doi:10.1038/s41598-019-51342-2

13. Notomi T, Okayama H, Masubuchi H, et al. Loop-mediated isothermal amplification of DNA. Nucleic acids research. 2000;28(12):E63. http://www.ncbi.nlm.nih.gov/ pubmed/10871386.
14. Zhang J, Cao J, Zhu M, Xu M, Shi F. Loop-mediated isothermal amplification-lateral-flow dipstick (LAMP-LFD) to detect Mycoplasma ovipneumoniae. World Journal of Microbiology and Biotechnology. 2019;35(2):1-10. doi:10.1007/s11274-019-2601-5

15. Zanoli L, Spoto G. Isothermal Amplification Methods for the Detection of Nucleic Acids in Microfluidic Devices. Biosensors. 2012;3(1):18-43. doi:10.3390/bios3010018

16. Hsiang MS, Greenhouse B, Rosenthal PJ. Point of Care Testing for Malaria Using LAMP, Loop Mediated Isothermal Amplification. Journal of Infectious Diseases. 2014;210(8):1167-1169. doi:10.1093/infdis/jiu253

17. Kaarj K, Akarapipad P, Yoon JY. Simpler, Faster, and Sensitive Zika Virus Assay Using Smartphone Detection of Loop-mediated Isothermal Amplification on Paper Microfluidic Chips. Scientific Reports. 2018;8(1):1-11. doi:10.1038/s41598-018-30797-9

18. Safavieh M, Kanakasabapathy MK, Tarlan F, et al. Emerging Loop-Mediated Isothermal Amplification-Based Microchip and Microdevice Technologies for Nucleic Acid Detection. ACS Biomaterials Science \& Engineering. 2016;2(3):278-294. doi:10.1021/acsbiomaterials.5b00449

19. Wang S, Lifson MA, Inci F, Liang L-G, Sheng Y-F, Demirci $\mathrm{U}$. Advances in addressing technical challenges of pointof-care diagnostics in resource-limited settings. Expert Review of Molecular Diagnostics. 2016;16(4):449-459. doi $: 10.1586 / 14737159.2016 .1142877$

20. Klatser PR, Kuijper S, van Ingen CW, Kolk AH. Stabilized, freeze-dried PCR mix for detection of mycobacteria. Journal of clinical microbiology. 1998;36(6):1798-1800. http:// www.ncbi.nlm.nih.gov/pubmed/9620427.

21. Espy MJ, Uhl JR, Sloan LM, et al. Real-Time PCR in Clinical Microbiology: Applications for Routine Laboratory Testing. Clinical Microbiology Reviews. 2006;19(1):165256. doi:10.1128/CMR.19.1.165-256.2006

22. Desjardin LE, Chen Y, Perkins MD, Teixeira L, Cave MD, Eisenach KD. Comparison of the ABI 7700 system (TaqMan) and competitive PCR for quantification of IS6110 DNA in sputum during treatment of tuberculosis. Journal of clinical microbiology. 1998;36(7):1964-1968. http://www.ncbi.nlm.nih.gov/pubmed/9650945.

23. Parikh R, Mathai A, Parikh S, Chandra Sekhar G, Thomas R. Understanding and using sensitivity, specificity and predictive values. Indian Journal of Ophthalmology. 2008;56(1):45. doi:10.4103/0301-4738.37595

24. Sharma GK, Mahajan S, Das BB, et al. Comparison of stabilisers for development of a lyophilised multiplex reverse-transcription PCR mixture for rapid detection of foot and mouth disease virus serotypes. Revue Scientifique et Technique de l'OIE. 2014;33(3):859-867. doi:10.20506/ rst.33.3.2323

25. Ryu YJ. Diagnosis of Pulmonary Tuberculosis: Recent Advances and Diagnostic Algorithms. Tuberculosis and Respiratory Diseases. 2015;78(2):64. doi:10.4046/ trd.2015.78.2.64

26. Nagaraj S, Ramlal S, Kingston J, Batra HV. Thermostabilization of indigenous multiplex polymerase chain reaction reagents for detection of enterotoxigenic Staphylococcus aureus. Journal of Microbiology, Immunology and Infec- 
tion. 2018;51(2):191-198. doi:10.1016/j.jmii.2016.04.004

27. Gaertig C, Niemann K, Berthold J, et al. Development of a point-of-care-device for fast detection of periodontal pathogens. BMC Oral Health. 2015;15(1):165. doi:10.1186/ s12903-015-0155-y

28. Khazani NA, Noor NZNM, Yean Yean C, Hasan H, Suraiya S, Mohamad S. A Thermostabilized, One-Step PCR Assay for Simultaneous Detection of Klebsiella pneumoniae and Haemophilus influenzae. Journal of Tropical Medicine. 2017;2017:1-8. doi:10.1155/2017/7210849

29. Gama JA, Abby SS, Vieira-Silva S, Dionisio F, Rocha EPC. Immune Subversion and Quorum-Sensing Shape the Variation in Infectious Dose among Bacterial Pathogens. Wessels MR, ed. PLoS Pathogens. 2012;8(2):e1002503. doi:10.1371/journal.ppat.1002503 